\title{
Anthropomorphizing Technology: A Conceptual Review of Anthropomorphism Research and How it Relates to Children's Engagements with Digital Voice Assistants
}

\author{
Janik Festerling $^{1}\left(\mathbb{0} \cdot\right.$ Iram Siraj $^{1}$
}

Accepted: 7 November 2021 / Published online: 23 November 2021

(c) The Author(s) 2021

\begin{abstract}
'Anthropomorphism' is a popular term in the literature on human-technology engagements, in general, and child-technology engagements, in particular. But what does it really mean to 'anthropomorphize' something in today's world? This conceptual review article, addressed to researchers interested in anthropomorphism and adjacent areas, reviews contemporary anthropomorphism research, and it offers a critical perspective on how anthropomorphism research relates to today's children who grow up amid increasingly intelligent and omnipresent technologies, particularly digital voice assistants (e.g., Alexa, Google Assistant, Siri). First, the article reviews a comprehensive body of quantitative as well as qualitative anthropomorphism research and considers it within three different research perspectives: descriptive, normative and explanatory. Following a brief excursus on philosophical pragmatism, the article then discusses each research perspective from a pragmatistic viewpoint, with a special emphasis on child-technology and child-voice-assistant engagements, and it also challenges some popular notions in the literature. These notions include descriptive 'as if' parallels (e.g., child behaves 'as if' Alexa was a friend), or normative assumptions that human-human engagements are generally superior to human-technology engagements. Instead, the article reviews different examples from the literature suggesting the nature of anthropomorphism may change as humans' experiential understandings of humanness change, and this may particularly apply to today's children as their social cognition develops in interaction with technological entities which are increasingly characterized by unprecedented combinations of human and non-human qualities.
\end{abstract}

Keywords Alexa · Anthropomorphism · Child development · Google Assistant · Human-computer interaction · Pragmatism · Social cognition · Voice assistants

Janik Festerling

Janik.festerling@education.ox.ac.uk

Extended author information available on the last page of the article 


\section{Introduction}

Through natural learning, humans develop understandings of their increasingly technologized environments long before they attend school (Papert, 1980). In this context, the earliest sphere of human development, the family home, sets the first primary stage for children's learning experiences, before their horizons begin to widen when they enter other childhood environments including their neighborhoods, pre-schools, primary schools or other family homes (Huston \& Ripke, 2006). Within these broader home and childhood environments, a global sociotechnical change has occurred over the last decade through the rise of commercially available Digital Voice Assistants (DVAs) like Amazon's ‘Alexa', Apple's 'Siri', or Google's 'Google Assistant' (Ammari et al., 2019; Beirl et al., 2019; Porcheron et al., 2018; Sciuto et al., 2018; Voit et al., 2020; Yuan et al., 2019; Beneteau et al., 2019; Festerling \& Siraj, 2020; Gao et al., 2018; Garg \& Sengupta, 2020; Lee et al., 2020; Lopatovska \& Williams, 2018; Lovato et al., 2019; Lovato \& Piper, 2015). One-third of US adults already own stand-alone DVAdevices (e.g., smart speakers (Kinsella \& Mutchler, 2020)), while forecasts predict the total number of DVA-enabled devices, which had already exceeded four billion in late 2020, will outnumber the human world population by 2024 (Moar \& Escherich, 2020).

Although DVAs may neither be the only nor the most sophisticated manifestations of intelligently behaving technologies, these individually and communally accessible voice interfaces are one of the most obvious experiences of artificial intelligence in today's home and childhood environments (Vlahos, 2019; Turk, 2016; Hoy, 2018; Hirschberg \& Manning, 2015). In contrast to smart toys and other technologies solely designed for children, DVAs' commercial ecosystems comprise a growing number of hardware (e.g., smart speakers, smart TVs, smartphones, smart home appliances, wearables, car entertainment systems) and software components (e.g., native and third-party DVA skills, professional/educational/medical DVA applications), which together are becoming omnipresent parts of everyday life (Small et al., 2018; Sweeney \& Davis, 2020; Trippas et al., 2019; Trivedi, 2018; Wang et al., 2019a; Alagha \& Helbing, 2019; Dousay \& Hall, 2018; Jargon, 2020; Perez, 2019; Pradhan et al., 2019; Ross, 2019; Sezgin et al., 2020; Skidmore \& Moore, 2019). In addition, preliminary research suggests DVAs' omnipresence across various devices at home is especially appreciated by families (Meurisch et al., 2020), further underpinning the relevance of DVAs in the context of developmental research.

But it is not only the growing socio-technical omnipresence of DVAs which could make them an important case for developmental research, but also their potential ontological momentum as experienced by today's children. DVAs are part of the human-technology dyad which has evolved since humans first used stones to break open coconuts or fallen trees to bridge rivers (Harwood \& Eaves, 2020). In this dyad, DVAs represent the stage of "autonomous technological beings" (Harwood \& Eaves, 2020, p.7), which are able to emulate peculiar qualities of human beings like language and speech, and, as Nass \& Brave 
(Nass \& Brave, 2005, p.3 emphasis in original) point out, "over the course of 200,000 years of evolution, humans have become voice-activated with brains that are wired to equate voices with people and to act quickly on that identification". However, it should also be remembered humans seem to have a natural tendency to 'equate' almost anything with people, and to act quickly on this identification through something formally known as anthropomorphism.

Anthropomorphism refers to the psychological phenomenon that humans tend to engage socially with non-human entities (e.g., technology, animals, plants, supranatural entities, natural or social phenomena) as if these entities were human. These humanlike engagements include their behaviors (i.e., how humans interact with non-human entities), their feelings (i.e., how humans feel about non-human entities) and their perceptions (i.e., how humans see and think about non-human entities) (Epley et al., 2007). ${ }^{1}$ This phenomenon is seen across various societal, cultural, religious and historical contexts (Guthrie, 1993), and has been scrutinized across diverse fields of research including psychology, neuroscience, psychiatry, philosophy, ethology and education (Varella, 2018). But since the growing digitization of the environment began in the second half of the twentieth century, anthropomorphism has become particularly relevant in addressing how humans engage socially with technology - with personal computers, basic robots, electronic toys etc. (e.g., (Reeves \& Nass, 1996; Turkle, 1984/2005)). With ongoing technological progress (e.g., smartphones, robotics, autonomous driving), anthropomorphism continues to be a popular research theme in the literature (e.g., (Turkle, 2017; van Straten et al., 2020; Wang, 2017; Waytz et al., 2014a)), and especially in the context of DVAs (e.g., (Voit et al., 2020; Gao et al., 2018; Lee et al., 2020; Lopatovska \& Williams, 2018; Pradhan et al., 2019; Biele et al., 2019; Motalebi et al., 2019; Purington et al., 2017; Wagner \& Schramm-Klein, 2019)).

Despite this wealth of material, little attention has been paid to the systematic differences between commercial DVAs and the animal-like or human-like technologies (e.g., Aibo, Robovie, Pepper, Nao, Kismet, iCat) and toys (e.g., Tamagotchi, Furby) often used in anthropomorphism research (Festerling \& Siraj, 2020). For example, most of these robotic technologies and toys convey the notion of being self-contained entities (i.e., entities which engage with their environments based on direct sensory input through cameras, microphones, or sensors, and which seem intelligent in the sense that they can somehow process this input internally). In contrast, children may experience DVAs as a different phenomenon, because they appear both to be omnipresent in various environments at the same time and to be intelligent in the sense that they are closely intertwined with sources above and beyond their physical boundaries (e.g., internet, smart home sensors). Furthermore, robotic

\footnotetext{
1 The review does not differentiate between anthropomorphism and animism. While the latter term refers more generally to cases in which humans engage with non-living entities as if they were alive, the former term refers only to those cases in which humans engage with non-human entities as if they were human (Guthrie, 1993). In addition, this review mainly focuses on anthropomorphism in the context of technology, which differs from anthropomorphism in other contexts (e.g., anthropomorphism in the ethological context of animal behavior) (Severson \& Woodard, 2018). Therefore, the review acknowledges any references to other contexts must be treated with caution.
} 
technologies and toys are often designed to convey strong visual and haptic experiences (e.g., human- or animal-like embodiments through eyes, mouths, ears, arms or legs), or to evoke caring or nurturing behaviors (e.g., feeding). As a consequence, such entities are usually limited to specific age ranges, and children eventually grow out of playing with them (Festerling \& Siraj, 2020). In contrast, DVAs are not limited to specific age ranges: their minimalistic physical designs (e.g., smart speakers) and utilitarian 'personalities' with a constantly growing number of functionalities and applications constitute an appeal to infants as well as elderly people, therefore turning DVAs into potential lifetime companions in their own right (Festerling \& Siraj, 2020). In the context of daily family life, this could mean that children rarely observe adults engaging socially with toys, yet they may often observe adults engaging socially with DVAs through human language and speech, therefore prompting children to conclude DVAs are serious voice-enabled engagement partners in their own right. Lastly, it should also be noted that although DVAs may be less embodied in terms of animal-like or human-like appearances (e.g., compared to robots), DVAs' are still physically embodied entities visually conveying socially salient cues (e.g., user-oriented display movement, pulsing light ring). ${ }^{2}$

The key question remains how anthropomorphism research relates to children who grow up amid increasingly intelligent and omnipresent technologies, particularly DVAs. This article suggests the answer may be less obvious than it seems. In particular, it is argued the nature of anthropomorphism may change as humans' experiential understandings of humanness change, and this may particularly apply to today's children who grow up amid increasingly intelligent and omnipresent technologies, such as DVAs. This article uses the methodological basis of a conceptual review, which means the synthesis of the interdisciplinary body of literature follows a conceptually framed process to address the key question of interest (Ayala, 2018; Parsons, 2016). The process is as follows: the first section reviews anthropomorphism research according to three different research perspectives (see research overview in supplementary material). Following a brief excursus on philosophical pragmatism, the second section then assesses how each of these perspectives relates to children who grow up amid increasingly intelligent and omnipresent technologies, such as DVAs. Finally, the last section summarizes the main arguments, outlines its limitations, and offers some directions for future research.

\section{What Is it? What Are its Consequences? What's Causing it? A Triadic View on Anthropomorphism Research}

Inspired by Epley's (2018) core questions which anthropomorphism research should address (e.g., 'What is it?', 'What are its consequences?', 'What's causing it?'), this section reviews anthropomorphism research according to three different research perspectives. The purpose of this triadic view on anthropomorphism research is to

\footnotetext{
${ }^{2}$ For this reason, we also find terms such as 'unembodied AI' problematic, because embodiment may rarely be determinable on a simple 'yes' or 'no' basis.
} 
provide a comprehensive account of contemporary anthropomorphism research in the context of human-technology engagements. Facing the trade-off between analytical scope and depth, the following review refers to 'technology' and 'social engagements' as rather broad categories comprising various types of technological entities and engagements (see research overview in supplementary material), while special attention is only paid to the peculiarities of children's engagements with DVAs. Although this is not without limitations, taking this approach is in line with the review's overall objective to look at the bigger picture of contemporary research investigating humans' engagements with technology, in general, and children's engagements with technology, in particular.

\section{What Is it? Anthropomorphism from a Descriptive Research Perspective}

From a descriptive perspective, anthropomorphism research uses human-human engagements as a benchmark to investigate empirically observable parallels to human-technology engagements. This is, to what extent humans seem to engage with non-human technology as if these technological entities were human beings.

Early empirical work which suggested human engagements with technology bear deep parallels with human-human engagement patterns (e.g., (Reeves \& Nass, 1996; Nass et al., 1993, 1994, 1996, 1999)) has been followed by an array of research on the different delineations and dependencies of anthropomorphism (for more details see research overview in supplementary material). For example:

- more humanlike appearances and behaviors of technological entities can directly increase how humans rate the entities' human-likeness and likability (e.g., (DiSalvo et al., 2002; Walters et al., 2008));

- more humanlike technological entities can convey signals of 'intention' (e.g., gazing) better to humans compared to less humanlike technological entities (e.g., (Mutlu et al., 2009));

- humans tend to engage in less abusive behaviors towards technological entities when the entities appear more intelligent (e.g., (Bartneck \& Hu, 2008));

- humans' trust in humanlike technological entities can be more resilient compared to their trust in less humanlike technological entities (e.g., (de Visser et al., 2016));

- voice-enabled technological entities can be held more morally accountable for their actions than simple technological entities without voice-interfaces (e.g., (Kahn et al., 2012a));

- technological entities with non-verbal emotional expressions, or with humanlike rather than robotic voices, can yield higher levels of acceptance and attachments in humans (e.g., (Eyssel et al., 2010, 2012)).

With regard to DVAs, humans who personify these voice-enabled technologies (e.g., referring to DVA with personal pronouns) tend to be more satisfied with their overall engagement experiences, and tend to cultivate more sociable relationships with them (Purington et al., 2017). Additionally, DVAs which emulate humanlike 
empathetic responses after being insulted (e.g., 'You're upset, let me know if there's something I can do better') can trigger feelings of guilt or mitigate aggressiveness in humans (Chin et al., 2020).

This suggests anthropomorphism requires the presence of humanlike 'triggers' in the environment (Waytz et al., 2014b, 2019), yet empirical research has shown humanlike engagement patterns with technological entities also depend on humans themselves. The patterns depend, for example:

- on humans' own gender or ethnicity, and how it matches technology's embodied gender or ethnicity (e.g., (Eyssel et al., 2012; Kamide et al., 2013));

- on humans' personalities (e.g., (Walters et al., 2008));

- on humans' socio-cultural backgrounds (e.g., (Evers et al., 2008));

- on humans' prior experience with technology (e.g., (Goudey \& Bonnin, 2016));

- on humans' needs and feelings for sociality or control (e.g., (Wang, 2017; Eyssel \& Reich, 2013; Kim \& McGill, 2011; Waytz et al., 2010a));

- on humans' age (e.g., (Kamide et al., 2013)).

However, the role of age in anthropomorphism remains intricate, or, as (Airenti, 2018, p.11) states, "the difference between adults and children is not qualitative but rather a matter of complexity". For example, although infants and young children often engage socially with non-human entities (e.g., toys) by pretending the entities are human (Airenti, 2015a), they also possess firm understandings of the ontological borders they cross and the behavioral commitments they make (e.g., imagination vs. reality) (Harris, 2000). This suggests children's anthropomorphism (as with adults') cannot be reduced to naïve confusions or infantile pretend play (Airenti, 2018; Severson \& Woodard, 2018; Severson \& Lemm, 2016).

Despite this considerable research about the nature of anthropomorphism in human-technology engagements, the "promiscuous use of the term" (Epley, 2018, p.594) in the literature suggests there is still little consensus about a precise definition of what anthropomorphism is and is not. Although the attribution of mental states (e.g., agency, motivations, interests, emotions, knowledge, sociality, moral worth and responsibility) lies at the heart of anthropomorphism for many authors (e.g., (Epley et al., 2007; Severson \& Lemm, 2016; Caporael \& Heyes, 1997; Fisher, 1996; Reiss, 2017; Severson \& Carlson, 2010; Urquiza-Haas \& Kotrschal, 2015)), other empirical studies suggest anthropomorphism it is not merely about the attribution of mental states; rather, it is about the holistic ontological concept of humanness people apply when engaging socially with non-human entities (Shaman et al., 2018). However, these underlying concepts of anthropomorphism (humanness vs. non-humanness) often seem too intricate to explicate, yet are appealingly intuitive to human audiences (Varella, 2018). It is, therefore, unsurprising that anthropomorphism research continues to explore almost any corner of the social experiences which humans can potentially have with other humans. This suggests the alleged 'promiscuity' more likely reflects what anthropomorphism research is about from a descriptive perspective: investigating parallels between the empirically observable patterns of human-technology engagements and the openly interpretable benchmark line of human-human engagements. Yet investigating parallelisms does not require 
consensus on the 'true' nature of the designated benchmark line (i.e., 'true' nature of human-human engagements), it only requires minimal consensus on what its designated endpoints are (i.e., human-human) in order to identify parallels between alternate endpoints (e.g., human-technology) - and there is, of course, little disagreement about who these living organisms, widely referred to as 'humans', actually are.

\section{What Are its Consequences? Anthropomorphism from a Normative Research Perspective}

As expressed by Epley (2018, p.695), something "that has no demonstrable consequences is not worth studying". The above discussion already suggests anthropomorphism has various consequences for human-technology engagements, but, from a normative perspective, the important question is how to evaluate such empirically delineated consequences.

On the one hand, these evaluations can yield concrete recommendations about how to improve technology's usability and effectiveness in human-technology engagements through the nuances of humanlike designs (e.g., (Waytz et al., 2014a; Breazeal, 2002; Duffy, 2003; Fong et al., 2003; Kiesler \& Hinds, 2004; Norman, 2005; Schmitz, 2010; Triberti et al., 2017; Waytz et al., 2010b)). Therefore, from a normative perspective, anthropomorphism research offers various potentials and opportunities to exploit the human tendency to engage socially with technological entities for meaningful and practical purposes. This is sometimes referred to as 'applied anthropomorphism' (Damiano \& Dumouchel, 2018). For example:

- naturalistic and humanlike movements can enhance technology's likeability (e.g., (Castro-González et al., 2016));

- technological entities endowed with conversational humanlike design components (e.g., microphones which look like ears; speakers which look like mouths) can give human users an immediate intuition of how to engage with them (e.g., (Złotowski et al., 2015));

- more humanlike technological entities can facilitate the collaborative effectiveness of human-technology engagements, or they can evoke socially desirable behaviors from humans - like refraining from harming the entity (e.g., (Bartneck \& Hu, 2008; Shah et al., 2011; Złotowski et al., 2014));

- engaging with humanlike technologies can serve as a 'scaffold' for children with autism to improve their social cognition (e.g., (Atherton \& Cross, 2018)).

But, evidently, whether the integration of humanlike design components is desirable also depends on the concrete applications for which technological entities are used (e.g., (Złotowski et al., 2015; Choi \& Kim, 2009; Collins, 2017; Goetz et al., 2003; Riether et al., 2012)), especially in the context of child-technology engagements (Pearson \& Borenstein, 2014). For example, although social robots have proven their promising potential as learning technologies (for reviews see (Belpaeme et al., 2018; Kanero et al., 2018; Papadopoulos et al., 2020)) - and this seems to hold true for DVAs as well (e.g., (Xu et al., 2021)) - children can also develop adverse 
responses to too much human-likeness (e.g., (Brink et al., 2019; Woods, 2006; Yip et al., 2019)), therefore echoing Mori's (Mori, 2012) widely-cited 'uncanny valley' theorem about the eeriness of almost perfect human resemblance.

On the other hand, the consequences of anthropomorphism in human-technology engagements have prompted researchers to evaluate the ethical risks of endowing technology with humanlike design components (Złotowski et al., 2015; de Graaf, 2016; Sætra, 2020, 2021a, 2021b). At their core, such ethical criticisms, sometimes referred to as the 'forensic problem of anthropomorphism' (Złotowski et al., 2015), consider the creation of humanlike technology as a form of deception, because they 'trick' humans, especially children, into overestimating the technology's 'true' capacities (Sharkey \& Sharkey, 2010), or into engaging with the technology in ways which are supposed to be reserved for genuine human-human engagements (Sætra, 2020). This may even culminate in the fear that humanlike technology could constitute a threat to human distinctiveness (e.g., (Ferrari et al., 2016; Porra et al., 2020)). At the forefront of this criticism, Turkle $(1984 / 2005,2017)$ has repeatedly emphasized how the temptations of engaging with technology, in general, and humanlike technology, in particular, appeal to human vulnerabilities rather than human needs, because the technological entities in question constitute seductive appeals to replace, denigrate, deny or degrade what deserves integrity: the existential value of humanhuman engagements. According to this normative perspective, no matter how authentic a technology's embodied human-likeness becomes in terms of its experienceable social qualities, and no matter how much humans appreciate and enjoy engaging socially with this particular technology, there remains an unambiguous normative hierarchy between engaging with 'simulations' of human nature and with human nature itself (Turkle, 1984/2005, 2017; Sætra, 2020). More recently, Turkle (2018) has re-emphasized this normative positioning in the context of DVAs by arguing children who engage with DVAs, and who may even develop social bonds or a sense of friendship with them, are ultimately at risk of 'forgetting what it means to be human'.

\section{What's Causing it? Anthropomorphism from an Explanatory Research Perspective}

At its core, anthropomorphism is a psychological phenomenon, and, as such, the causes of its origins and variability must be explainable by psychological mechanisms (Epley, 2018). From an explanatory research perspective, this means there must be a psychological reasoning for the question why humans tend to engage socially with non-human technology as if these entities were humans. The answer lies in the heart of human social cognition.

Social cognition seems to be a particularly strong quality of human intelligence compared to other primate species (Herrmann et al., 2007), and there are good reasons to assume the foundations of social cognition are innate due to their early manifestations in human development (e.g., (Airenti, 2015b; Kovacs et al., 2010; Onishi \& Baillargeon, 2005; Perner \& Roessler, 2012; Southgate et al., 2007)). As humans develop, social cognition culminates, among other things, in the ability to infer and contemplate the intricate perspectives of others in their beliefs, interests 
and motivations for action - usually referred to as 'Theory of Mind' (ToM) (Wellman, 2014). But what about non-human others?

Social cognition is a pervasive psychological ability, and, consequently, anthropomorphism should not be reduced to "a by-product of misplaced social cognition [...]; rather [it is] an unavoidable consequence of the functional organization of the human brain" (Urquiza-Haas \& Kotrschal, 2015, p.171). For example, children's early ability to evaluate the passively observed social behaviors of others (Hamlin et al., 2007) seems to extend naturally to human-technology engagements, as exemplified by 18-month-old infants who can already recognize whether a robot engages in socially contingent dialogues with adults (Meltzoff et al., 2010). Furthermore, neuroscientific evidence suggests the same neural mechanisms of social cognition (e.g., attribution of mental states to others, responding to facial expressions) are also at work when humans anthropomorphize non-human entities (e.g., (Castelli et al., 2000; Chaminade et al., 2007; Cullen et al., 2014; Dubal et al., 2011; Gazzola et al., 2007; Gobbini et al., 2010; Scheele et al., 2015)).

From an evolutionary perspective, this propensity of social cognition to be triggered by human and non-human entities can be explained as an adaptive survival mechanism. In primeval environments, which had the greatest evolutionary impact on the development of the 'modern' human brain (Cosmides et al., 1992), it was a more effective strategy to behave falsely as if something was alive and similar to oneself, and a more fatal strategy to behave falsely as if something was inanimate and without agency or intelligence (e.g., (Guthrie, 1993; Atran \& Norenzayan, 2004)). Notably, even today individual tendencies to anthropomorphize non-human entities are positively associated with other evolutionary salient behaviors (e.g., hoarding) (Timpano \& Shaw, 2013), and also other non-human primate species (e.g., chimpanzees) tend to engage socially with technological entities when the entities imitate the bodily movements of the animal engagement partner (Davila-Ross et al., 2014).

In line with this brief account of social cognition, Epley et al.'s (2007) widelycited three-factor theory assumes anthropomorphizing non-human entities follows the same cognitive process of inductive inference which also orchestrates humanhuman engagements, namely inferring concrete assumptions and predictions about the otherwise opaque inner nature of social engagement partners. According to Epley et al. (2007), this inference is anchored in the inductive base of humanness, in humans' deeply ingrained knowledge about the self in particular (i.e., direct phenomenological experience of being human resulting in egocentric knowledge), and about humans in general (i.e., experience-based knowledge of humans resulting in homocentric knowledge). Although it is challenging to disentangle the ego- and homocentric cognitive basis of anthropomorphism (see (Kwan et al., 2008)), it is important to note human social cognition offers different routes, ranging from using one's own mind for simulating the mental processes of others (e.g., mirroring, selfprojection), to using more abstract and knowledge-based forms of inference (e.g., mentalizing) (Van Overwalle \& Baetens, 2009; Waytz \& Mitchell, 2011). Furthermore, this readily accessible cognitive anchor of humanness is co-determined by two fundamental motivational forces, namely sociality motivation (i.e., human desire to seek social connections, approval, support etc.) and effectance motivation (i.e., human desire to gain efficacious cognitive control over one's environment) (Epley 
et al., 2007). These motivational co-determinants are important factors in explaining the empirically observable variability of anthropomorphism across humans (e.g., (Wang, 2017; Waytz et al., 2010a; Epley et al., 2008)), and they can also account for the presence of anthropomorphism in populations with impaired social cognition (e.g., autism) (Atherton \& Cross, 2018). However, the inductive base of humanness as the cognitive anchor of anthropomorphism, and its co-determinants of sociality and effectance motivation, are far from uniform, especially when comparing urban and rural populations (e.g., (Herrmann \& Atricia, 2010; Medin et al., 2010)). Therefore, as outlined by Epley et al. (2007), the full variability of anthropomorphism can be explained only by taking into account the dispositional, developmental, situational and cultural sub-determinants of each factor (see Fig. 1).

\section{A Pragmatistic View on Anthropomorphism Research in the Context of Children and DVAs}

The current understandings of anthropomorphism, as reviewed above, seem to assume the dualistic concepts of humanness and non-humanness, which define the existence of anthropomorphism, bear a metaphysical truth (i.e., represent true ontological delineations). But what if there is no metaphysical truth to such concepts? What if these concepts are epistemological instruments made up by the clever animals (i.e., humans) who use them? In other words, what if "truth, at its core, is not a metaphysical category but rather a moral and epistemological one" (Suckiel, 2006, p.37)? This is the provoking story of philosophical pragmatism, particularly one of its variants referred to as instrumentalism or constructive empiricism (Misak, 2006), which dates back to the classical pragmatist William James (e.g., (James, $1967,1907 / 2010,1912 / 2012))^{3}$

Despite the different nuances which have evolved since its emergence in the late nineteenth century, classical pragmatism shares three philosophical themes: (1) the active and subjective role of the interpretative human mind in scientific and non-scientific knowledge acquisition; (2) the fallible and non-apodictic nature of knowledge due to its reliance on human experience; and (3) the rejection of foundationalist truths and certainties such as the Cartesian mind-body dualism (McDermid, 2006). These themes are certainly not exclusive to pragmatism per se, because as a rather heterogenous tradition, it has shares overlaps with other philosophical paradigms. For instance, pragmatism's adherence to a mind-independent reality follows the rationale of realism. However, rather than assuming that realism allows us to get reality objectively 'right', it is considered a hypothesis we need to be able to learn by experience (McDermid, 2006;

\footnotetext{
3 In contrast to Servais' (2018) pragmatistic account of anthropomorphism research, which argues an entity's inner state (e.g., intentions, feelings) is directly perceivable without the need for inference (e.g., (Gallagher, 2008)), this review's pragmatistic view on anthropomorphism research commits to the 'anthropomorphism-as-inference' approach, such as Epley et al.'s (2007) three-factor theory.
} 
(I) Inductive base: ego- or homocentric knowledge about humanness

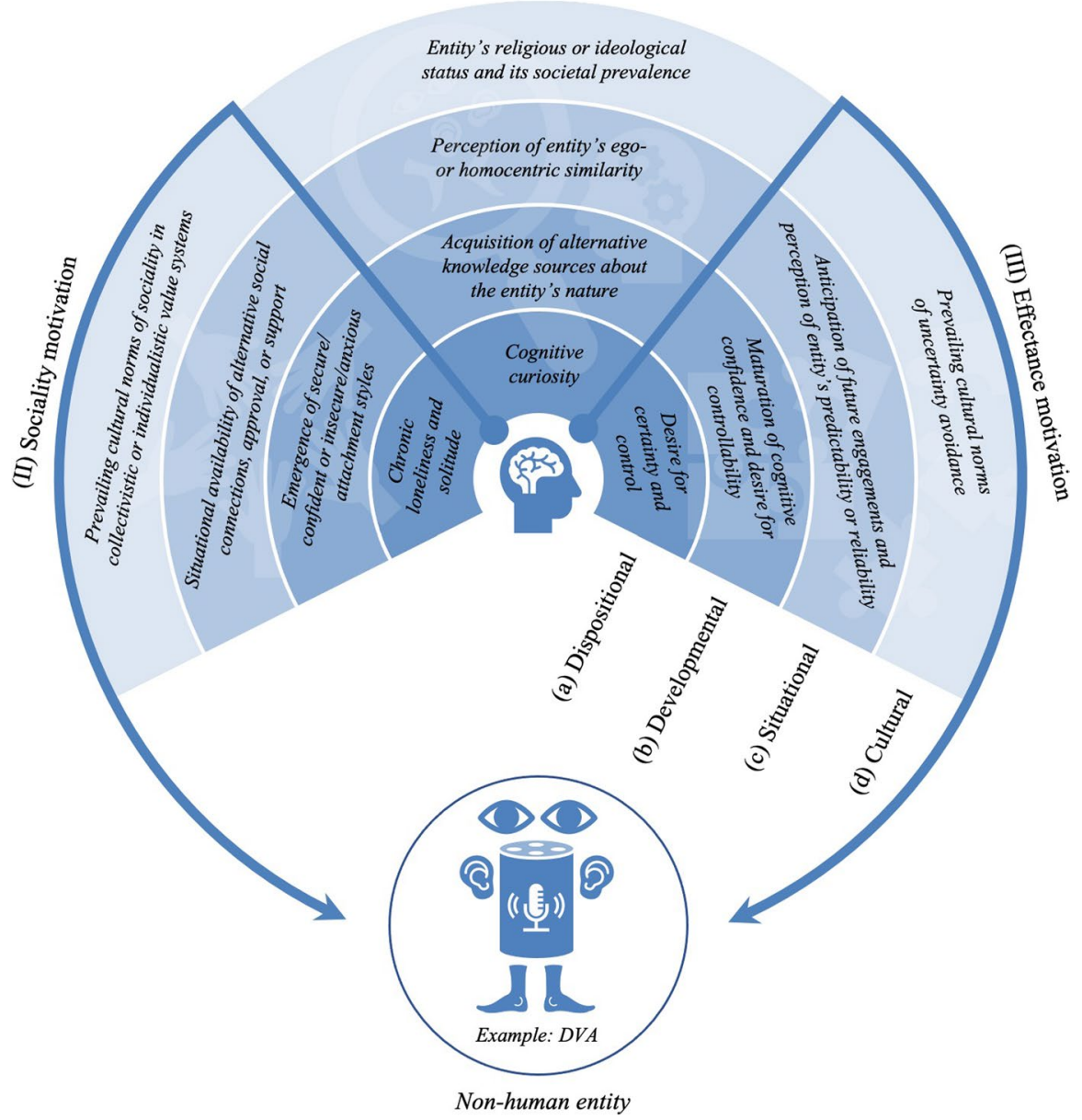

Fig. 1 Determinants of anthropomorphism based on Epley et al.'s three-factor theory. Notes. Figure visualizes anthropomorphism according to Epley et al.'s (2007) three factor theory of anthropomorphism. Circular segments (I to III) visualize determinants of anthropomorphism: (I) inductive base of ego- or homocentric knowledge about humanness (cognitive determinant), (II) sociality motivation (first motivational co-determinant), and (III) effectance motivation (second motivational co-determinant). Different shades within each circular segment show examples for (a) dispositional, (b) developmental, (c) situational, and (d) cultural sub-determinants. Figure displays a DVA as an example of a non-human entity. Some key terms have been adjusted compared to Epley et al.'s (2007) original terminology (e.g., 'need for cognition' $\rightarrow$ 'cognitive curiosity'). Source. Developed from Epley et al. (2007)

Rescher, 2006). For Jamesian pragmatism, this process of learning by experience is teleological in nature, meaning human cognition is always subject to individual motivations and interests (Suckiel, 2006). Therefore, beliefs about knowledge and truth must always be viewed in light of the believers' motivations and interests, 
and, as James' (1902/2013) work on religious experiences suggests, knowledge is true insofar as it has real consequences for those who believe in it.

From this pragmatistic viewpoint, the dualistic concepts of humanness and nonhumanness are understood as functional distinctions for dealing with reality, and as true only insofar as they are practically useful for those who believe them according to their motivations and interests (Suckiel, 2006; Sprigge, 2006). In other words, pragmatism it is not repudiating dualistic concepts as such; rather, it is less concerned with their metaphysical validity and considers that "supposedly sharp distinctions may be better conceived as lines of demarcation drawn at some point on a continuum" (Haack, 2006, p.152). The question remains what a pragmatistic view on anthropomorphism research means in the context of children who grow up amid increasingly intelligent and omnipresent technologies, such as DVAs. Following Servais' (2018) recent pragmatistic account of anthropomorphism research in the context human-animal engagements, the main starting point is to focus less on a priori certainties and to prioritize the nuances of human experiences, such as children's subjective experiences when engaging with DVAs in their home and childhood environments. Based on the three research perspectives reviewed above, this is discussed in more detail in the following.

\section{Pragmatistic View on the Descriptive Research Perspective}

From a descriptive perspective, anthropomorphism research uses human-human engagements as a benchmark to investigate the extent to which humans engage with non-human technological entities as if these entities were human beings, while there is still little consensus about what a definition of anthropomorphism should comprise, as reflected by the wide range of interpretations in the literature (Epley, 2018).

But is it feasible, from a pragmatistic viewpoint, to call for more clear-cut conceptual boundaries of anthropomorphism (see (Epley, 2018))? This intention seems noble, but the philosophical subtext of defining clear-cut boundaries would be that there were corresponding metaphysical categories of the human and the nonhuman. From a pragmatistic viewpoint, this would be an epistemological arrogation, because such boundaries represent only human-made lines drawn on some continuum for practical purposes and without any finality in meaning. This is partly reflected by the gradual decline of traditional anthropomorphism research which equates humanlike engagement patterns with genuinely 'false' behaviors or beliefs (e.g., behaving falsely as if something was human). For example, the recent anthropomorphism literature on human-animal engagements suggests "much of what has been considered as anthropomorphic interpretations may in fact do more justice to the mental states of other animals than was previously believed" (Urquiza-Haas \& Kotrschal, 2015, p.168), such as 'behaving as if dogs really understand what humans say' (see (Andics et al., 2016)). However, should the arguments be different for human-technology engagements (as compared to human-animal engagements)? In other words, is it not possible to be more certain about the things which differentiate humans from the things they have created themselves (e.g., DVAs)? A pragmatistic answer would be to ask whether these are the most useful questions to ask for 
the investigation of human-technology engagements from a descriptive perspective. After all, it lies in the nature of a continuum that it is "constituted as much by difference as by similarity" (Alexander, 2006, p.189, emphasis added).

On the continuum of social engagements, human-technology engagements circumscribe one of the infinitesimal variations of engaging socially with one's environment. Yet to be on this continuum in the first place is simply an all-or-nothing question, because, as Seibt (2017) points out, social engagements of any kind require a basic social commitment, which can either be undertaken or not, but it must always be real. In the words of Seibt (2017, pp.18-19, emphasis in original): "pretending to undertake a commitment is simply to fail to undertake it. [...] Making a promise or treating someone as a person are real social interactions by virtue of engaging in a certain declarative practice". On this basis, claiming children or adults engage socially with a technology 'as if' it was a human remains misleading: they either engage socially with it in one way or another, or they do not; but if they do, they have granted it the status of a social engagement partner in its own right. Moreover, and in line with the pragmatistic adherence to realism, Seibt (2017) emphasizes social engagements of any kind emerge from the reality of experienceable social behaviors as they are displayed by social engagements partners (e.g., facial expressions, language), regardless of whether these behaviors are deemed authentic or not. As Seibt (2017, pp.19-20, emphasis in original) writes:

[I]t is an obvious requirement of social praxis that the performance conditions of a social interaction [...] must relate only to behavioral criteria and cannot take intentional states into account. [...] [C]harges about someone's performing a social action inauthentically or insincerely relate to the quality of the social action, not to [its] occurrence.

Both issues raised by Seibt (2017) seem particularly relevant in the context of DVAs. Alexa, the Google Assistant, Siri or other DVAs are designed to engage with humans through sophisticated social behaviors, namely the autonomous use of human language and speech (Festerling \& Siraj, 2020). In light of such strong "behavioral realism" (Damiano \& Dumouchel, 2018, p.3), the commitments of social engagement are supposedly easily undertaken (e.g., similar to the social behaviors displayed by animals) (Severson \& Lemm, 2016), therefore granting DVAs the status of being social engagement partners in their own right - irrespective of whether their behaviors are perceived as being authentic or not. For empirical research, the pragmatistic viewpoint suggests children's social engagements with DVAs reflect how they subjectively experience what they deem significant in terms of sociality, and that the nature of their engagements with DVAs reflects how they translate this experience of sociality into real social behaviors. Accordingly, the description that children engage with DVAs 'as if' these technological entities were friends, playmates, companions or simply humans, may not adequately capture what children subjectively experience.

In summary, narrowing the scope of anthropomorphism research by defining more precise conceptual boundaries is not a feasible endeavor. From a descriptive perspective, anthropomorphism research should continue to explore the infinitesimal variations of how children and adults engage socially with human or non-human 
entities in their environments, and to be informed or inspired by a general familiarity with human-human engagements - but not as an absolute and a priori defined benchmark.

\section{Pragmatistic View on the Normative Research Perspective}

The above discussed pragmatistic view on anthropomorphism draws special attention to the normative issue of what humans deem worth engaging with, and whether granting the status of social engagement partners to technological entities (e.g., DVAs) could not only ennoble the technology but also degrade the human by deflating the unique social value of human-human engagements (e.g., (Turkle, 1984/2005, 2017)). However, can these concerns stand up to pragmatistic scrutiny?

The basic ethical criticism of endowing technology with humanlike design components is an inheritance from Descartes' dualism (Descartes, $1649 / 1988,1641 / 1998)$, especially regarding the strict ontological dichotomy of the mindful and the mindless, or the human and the non-human (Damiano \& Dumouchel, 2018; Bruni et al., 2018). One of the most influential criticisms following this Cartesian legacy has been Turkle's (1984/2005, 2017) hierarchical distinction between technology's inferior simulation of mentation, intentionality or emotionality, and the superior genuineness of human mentation, intentionality or emotionality (Damiano \& Dumouchel, 2018). Pragmatism is generally suspicious of drawing such apodictic conclusions from Cartesian a priori dualisms (McDermid, 2006), and it asks whether such an uncompromising hierarchization of superior human-human and inferior human-technology engagements can be justified by the normative virtues of human experience. This seems, at best, questionable, because such a hierarchization would ignore that, at times, humans could systemically prefer to engage with humanlike technology due to, rather than despite of, the absence of what they think constitutes 'true' humanness.

For example, there is comprehensive clinical research on how humans are more willing to self-disclose sensitive personal information to technology (e.g., human physician vs. virtual humanlike physician), and most findings suggest humans systematically prefer to self-disclose more sensitive personal information with nonhuman technological entities (Bickmore et al., 2005; DeVault et al., 2014; Kissinger et al., 1999; Lucas et al., 2014; Yokotani et al., 2018). Given technology's absence of moral judgement, this may not be a convincing point to make on its own, because the same reasoning would also apply to non-judgmental diaries people write. However, in combination with other empirical findings, one could argue such self-disclosure patterns reflect a more general tendency of humans to differentiate and appreciate certain variations of social engagements according to the perceived strengths and weaknesses of human or non-human engagement partners. For example, Logg et al. (Logg et al., 2019) showed how humans tend to place more trust in predictions and judgements from a technological entity (i.e., algorithm), while, according to Ha et al.'s (Ha et al., 2020) experimental research on privacy concerns and self-disclosure, humans tend to mistrust technological entities which seem too humanlike 
(e.g., using emotional conversational tones, pro-actively addressing human users), or which present themselves as 'partners' rather than 'servants'.

Similar nuances can also be found in children's engagements with technological entities. For example, some children in Turkle's (2017) ethnographic studies provided well-argued reasons why the programmable nature of technology would make them more reliable, consistent and trustworthy than humans. When it comes to DVAs, in particular, the exploratory qualitative findings by Festerling \& Siraj (2020) on children's open engagements with DVAs suggest children seem to appreciate the instant social gratification and excitement they experience with DVAs, and they also associate DVAs with relative ontological strengths. For instance, children systematically attributed higher accuracy levels and faster response times to DVAs for knowledge-related domains of intelligence (e.g., provision of facts), and explained their attribution patterns by DVAs' connectedness to the internet and their programmable nature (Festerling \& Siraj, 2020). This is in line with other empirical findings in the literature on children's differentiated perceptions of technology as data-based knowledge sources (e.g., (Rücker \& Pinkwart, 2016; Wang et al., 2019b)). However, Oranç \& Küntay (2020) found even when children think technological entities are intelligent enough to answer questions related to mechanical or electronic issues, for biological and psychological issues (e.g., 'Why do humans sleep?', 'Why do people help each other?'), children still prefer humans as knowledge sources. Similarly, Festerling \& Siraj (2020) also found children associate other domains of intelligence with humans (e.g., conversational comprehension, common sense, creativity), which is further in line with Xu et al.'s (2021) experimental findings on how children seem to elevate the intelligibility of their speech according to DVAs' perceived conversational weaknesses. Lastly, Yip et al.'s (2019) found although children expect a DVA to make them laugh in response to certain commands (e.g., commands to make farting noises), a DVA that would laugh itself was thought of as being utterly disturbing.

In summary, the pragmatistic reading of these empirically observable nuances is that children's engagements patterns with technological entities already follow nuanced understandings and expectations regarding the entities' experienceable strengths and weaknesses. This further suggests human-technology engagements are irreducible experiences in their own right on the continuum of social engagements, and, vis-à-vis human-human engagements, the relationship is as much about relative differences as about similarities.

Importantly, although this pragmatistic line of reasoning challenges traditional ethical criticisms which emerge from dualistic viewpoints on reality, it does not negate ethical issues. As Damiano \& Dumouchel (Castro-González et al., 2016) show in their account of 'synthetic ethics', creating technology inspired by an understanding of, and knowledge about, humanness requires ethical sensitivity towards concrete issues which could arise in the context of application, and a solution-oriented attitude to address these issues without condemning humanlike technology as a whole. For example, the above discussed use of technology in clinical contexts prompts a question about which humanlike design components could compromise a technology's usability and effectiveness (see (Bartneck et al., 2010)) which may also be true for other professional contexts (Riether et al., 2012). Furthermore, child-DVA engagements raise additional questions about how DVAs are supposed to 
handle morally sensitive situations: these include offensive voice commands (UNESCO and EQUALS Skills Coalition, 2019), the close emotional attachments vulnerable children may develop with them (Garg \& Sengupta, 2020), and the potential societal harm from using primarily female voice-interfaces (Wang, 2019).

\section{Pragmatistic View on the Explanatory Research Perspective}

In a recent experimental study ( $n=144$, age: 8-9 years), van Straten et al. (2020) hypothesized children's humanlike perceptions of a robot were due to insufficient awareness about the robot's lack of 'true' humanness, as exemplified by its programmability. To address the ambiguity of their empirical findings, van Straten et al. (2020) conclude:

Perhaps it can simply not be assumed that children understand that a humanoid robot is more similar to a technology than to a human being, even if this is pointed out repeatedly and even if children understand that a robot is not humanlike in terms of psychological capacities (p. 12).

But what if researchers' claims that children anthropomorphize technological entities were simply artefacts of false understandings of what is unique to humans and technology - 'false' in the sense it differs from the perspective of today's children who develop their own understandings of these concepts. In other words, the nature of anthropomorphism could change as humans' experiential understandings of humanness change, and this may particularly apply to today's children who are growing up amid technologies which, for example, can emulate the autonomous use of human language and speech. In this case, the claim children anthropomorphize DVAs would be an artefact of an 'anachronistic' understanding of humanness and technology - at least from the perspective of children who have been intimately exposed to these voice-enabled technological entities from the beginning of their lives. Or, as put more generally by Damiano and Dumouchel (2018), p.4), with technological progress blurring the experienceable boundaries between humans and technology, "the question of what constitutes human identity, or particularity, is raised anew". At its core, this is a pragmatistic line of reasoning regarding the explanatory origins of anthropomorphism, because it prioritizes experiential understandings of humanness over a priori derived ones. But what are the supporting arguments for this reasoning?

According to Epley et al.'s (2007) previously mentioned three-factor theory, the process of cognitive inference which causes anthropomorphism psychologically is anchored in the inductive base of humanness (i.e., humans' deeply ingrained knowledge about the self in particular, and about humans in general). However, could children's experience of engaging socially with DVAs from the very beginning of life impact the development of this inductive base of humanness? It is beyond the scope of this review to provide a definite proof for this hypothesis, but there are two noteworthy empirical studies that can support this proposition.

First, in a recent neuroscientific study, Waytz et al. (2019) investigated anthropomorphism in amygdala-damaged patients (and a control group) to isolate two 
neuronal processes: the bottom-up process of anthropomorphism based on overt social behaviors (e.g., facial expressions and motion patterns displayed by a dog), and, in the absence of overt social behaviors, the top-down process based on abstract semantic knowledge about socially meaningful stimuli in the environment (e.g., inferences made from more nuanced social stimuli displayed by a robot). As noted by Waytz et al. (2019), these findings support the general notion that anthropomorphism, as part of social cognition, offers different routes, and that at least one of these routes seems to be based on things humans gradually learn through social experiences as they develop.

Second, in a recent experimental study, Brink et al. (2019) investigated how the 'uncanny valley' unfolded in a developmentally diverse sample ( $n=240$, age: 3-18 years). In particular, the study examined whether the uncanny valley constitutes an innate aversion due to evolutionary determined responses to physiological illnesses and defects, which would further imply that even the youngest infants in the sample should display aversions towards overly humanlike technology, or whether it constitutes a violation of postnatally acquired expectations and norms about humanness and technology, which are only developed throughout childhood as part of social learning experiences (Brink et al., 2019). The empirical results revealed an unambiguous pattern: aversions towards overly humanlike technology seem to develop with age, but not before middle childhood (9-11 years), therefore providing strong empirical support for the latter origin of the uncanny valley (Brink et al., 2019).

Taken together, both studies suggest the human stance towards technology is at least partly shaped by children's developing understandings of the social realities they face. In consequence, this would imply that the inductive base of anthropomorphism, as circumscribed in Epley et al.'s (2007) three-factor theory, could also change through changing social realities. The reality for many children today is both that they can engage with technology through human language and speech, and that these technologies are firmly embedded in social life at home (Ammari et al., 2019; Beirl et al., 2019; Porcheron et al., 2018; Voit et al., 2020; Garg \& Sengupta, 2020; Lee et al., 2020).

This pragmatistic view on anthropomorphism echoes previous discussions in the literature on Kahn et al.'s (2006, 2007, 2011, 2009, 2012b) 'new ontological category hypothesis', stating increasingly intelligent technologies could become an independent and developmentally stable ontological category in its own right which cuts across traditional ontological dichotomies (e.g., animate vs. inanimate, human vs. non-human). Implications, challenges and potential empirical validations of the new ontological category hypothesis have already been discussed elsewhere (e.g., (van Straten et al., 2020; Severson \& Lemm, 2016; Severson \& Carlson, 2010; de Graaf, 2016; Seibt, 2017; Oranç \& Küntay, 2020; Levillain \& Zibetti, 2017; Melson et al., 2009; Bernstein \& Crowley, 2008; Gaudiello et al., 2015; Jipson et al., 2016; Kim et al., 2019)), and also in the particular context of DVAs (e.g., (Festerling \& Siraj, 2020; Pradhan et al., 2019)). However, this review adds that the new ontological category hypothesis is philosophically grounded in a pragmatistic paradigm, because the underlying assumption is that children's developing ontologies, as reflected by their conceptual understandings of the world around them, may not 
converge to an a priori definable and metaphysically 'true' end-state. In the words of James (1912/2012, p.114): “[o]ur ideas and concepts and scientific theories pass for true only so far as they harmoniously lead back to the world of sense".

\section{Conclusion, Limitations, and Future Research}

This conceptual review article, addressed to researchers interested in anthropomorphism and adjacent areas related to human-technology or child-technology engagements, has aimed to provide a conceptually framed account of contemporary anthropomorphism research based on three different research perspectives (descriptive, normative, and explanatory). Moreover, it has applied a pragmatistic viewpoint (mainly inspired by Jamesian pragmatism and related works) to discuss how these perspectives may contribute to a scientific understanding of children's engagements with increasingly intelligent and omnipresent technologies such as DVAs. The pragmatistic viewpoint sheds a new light on widely held views in the literature (e.g., descriptive 'as if' claims, normative hierarchies between human-human and humantechnology engagements), culminating in the argument that, from an explanatory perspective, the nature of anthropomorphism may change as humans' experiential understandings of humanness change, and that this may particularly apply to today's children as their social cognition develops in interaction with technological entities which are increasingly characterized by unprecedented combinations of human and non-human qualities.

Besides the methodological limitations inherent to conceptual reviews (Parsons, 2016), the article's main limitation lies in the trade-off choice between analytical scope and depth: to increase the scope of the discussion, the article referred to 'technology' as a rather broad category comprising various types of technological entities and social engagements (see research overview in supplementary material), while special attention was only paid to the peculiarities of children's engagements with DVAs. Narrowing the scope to certain types of technology or social engagements would have partly increased the depth of the discussion. However, the aim of this article was to look at the bigger picture of anthropomorphism research investigating humans' engagements with technology, in general, and children's engagements with technology, in particular. As such, the question whether the technology under investigation is specifically designed for social purposes is not of primary importance, because, as the above discussion suggests, there are infinitesimal variations of how technology can be anthropomorphized, and these occur across a broad range of design and research contexts.

The article points in three main directions for future research. First, recent empirical studies which investigated traditional anthropomorphism issues in humantechnology research from a developmental perspective (e.g., developmental origins of the uncanny valley by Brink et al. (Brink et al., 2019)) already showed how the investigation of children can contribute to the research field more generally. Future research could use similar cross-sectional or experimental age group comparisons to investigate how children's daily exposure to certain types of technology (e.g., DVAs) may influence such developments. For instance, Bernstein \& Crowley's (Bernstein 
\& Crowley, 2008) original, and, up to this point, un-replicated finding that children born in the early 2000s with high exposure to robotic technologies have a different conceptual understanding of intelligence and aliveness raises overdue empirical questions in light of hundreds of millions of DVAs being installed in home and childhood environments across the globe in the early 2020s. Following the pragmatistic viewpoint of the above discussion, such future research should be less concerned with the question whether children develop an 'objectively true' understanding of technology (see (van Straten et al., 2020)) and more open towards new ways about thinking about their increasingly technologized environments (Festerling \& Siraj, 2020).

Second, research on children's understandings of state-of-the-art technology is trying to capture a fast-moving target, especially in the context of commercially available technologies such as DVAs. Unlike many other types of technologies often investigated in anthropomorphism research, DVAs not only stand out in terms of how fast they have populated home and childhood environments at large scale but also how fast their designs and technological capacities to emulate human language and speech change. Therefore, DVAs remain a highly relevant yet challenging case for research in their own right, and particular attention should be paid its technological development. For instance, so far DVAs' human-like design has been limited to the autonomous use of human language and speech, but smart speakers could soon also be able to move autonomously (e.g., turning screens according to user movements in the room) (Amazon Day One Staff, 2020). The utilitarian importance of such technological developments may be unclear, but given coherent motion patterns are a salient stimulus for innate social cognition in their own right (e.g., (Meltzoff et al., 2010; Bertenthal et al., 1987; Simion et al., 2008)), they could be important in children's developing understandings of DVAs. In this context, children with disabilities and their caregivers will be a subpopulation of particular importance, given DVAs' (future) potential to inform, assist, assess and support these individuals with special developmental or medical needs (Sezgin et al., 2020). Preliminary research already suggests commercial off-the-shelf DVAs are popular among individuals with disabilities (e.g., (Pradhan et al., 2018; Duffy et al., 2021)), but research is still limited, especially when focusing on concrete disabilities (e.g., (Cave \& Bloch, 2021)). However, apart from general socio-economic and skill-related accessibility issues (Paul et al., 2021), children with different kinds of disabilities will experience different kinds of benefits and challenges. For instance, visually impaired children are likely to benefit from the functional advantage of DVAs' hands-free and 'eye-free' voice interfaces, but, at the same time, today's DVAs usually lack the customizability to address certain special needs, such as longer response times, faster speech rates, or custom voice commands (Branham \& Mukkath Roy, 2019). Nevertheless, future research should not only consider DVAs as a functional means to a social end for children with disabilities (e.g., by using text-to-speech functions to socially connect with peers online, see (Paul et al., 2021)), but also as a social end in itself (e.g., by serving as a humanlike 'scaffold' to improve social cognition, see (Atherton \& Cross, 2018)).

Third, the pragmatistic view on anthropomorphism can be extended by what neopragmatists (e.g., (Rorty, 1982, 1998, 2006)) say about the critical role of language 
in inquiry. In fact, human cognition is significantly shaped by the languages spoken (Haun et al., 2006), and in the context of anthropomorphism, determining the 'true' meaning of what humans say about or to non-human entities remains challenging from a research perspective (Damiano \& Dumouchel, 2018; Złotowski et al., 2015). For example, the use of gendered personal pronouns in human-DVA engagements has been interpreted as a direct signifier for the personalization of DVAs (e.g., (Gao et al., 2018; Pradhan et al., 2019; Purington et al., 2017)). Future research could be more critical of the role of language in anthropomorphism by examining the psychological mechanisms (e.g., sociality or effectance motivation) which cause the development of particular language patterns in human-technology engagements (e.g., referring to DVAs with personal pronouns).

Lastly, it is worth pointing out that our discussion is 'bent towards a particular perception of science'. In particular, the notion of pragmatism we follow lends itself to an empirically grounded perspective to look at things, that is, a perspective which favors "a [constructivist] model of children as builders of their own intellectual structures" (Papert, 1980, p.7), rather than a model of children as recipients of a priori defined intellectual structures we already built for them. Developmental constructivism - at least in its original epistemological form - has traditionally been criticized for not having a socio-cultural lens (Chapman, 1988), and readers who feel more inclined towards this criticism will naturally entertain doubts about the ideas and arguments discussed above. Yet, we hope our paper widens the thinking on children's development in the context of modern everyday technology, and how social cognition of today's children develops in interaction with technological entities which are increasingly characterized by unprecedented combinations of human and non-human qualities.

Supplementary Information The online version contains supplementary material available at https://doi. org/10.1007/s12124-021-09668-y.

Author Contributions The first author conceived the original idea, developed the research, and wrote the manuscript. The second author provided critical feedback and helped shape the research and the final manuscript.

\section{Declarations}

Conflict of Interest The authors declare that the research was conducted in the absence of any commercial or financial relationships that could be construed as a potential conflict of interest.

Open Access This article is licensed under a Creative Commons Attribution 4.0 International License, which permits use, sharing, adaptation, distribution and reproduction in any medium or format, as long as you give appropriate credit to the original author(s) and the source, provide a link to the Creative Commons licence, and indicate if changes were made. The images or other third party material in this article are included in the article's Creative Commons licence, unless indicated otherwise in a credit line to the material. If material is not included in the article's Creative Commons licence and your intended use is not permitted by statutory regulation or exceeds the permitted use, you will need to obtain permission directly from the copyright holder. To view a copy of this licence, visit http://creativecommons.org/licen ses/by/4.0/. 


\section{References}

Airenti, G. (2015a). The cognitive bases of anthropomorphism: From relatedness to empathy. International Journal of Social Robotics, 7(1), 117-127. https://doi.org/10.1007/s12369-014-0263-X

Airenti, G. (2015b). Theory of mind: A new perspective on the puzzle of belief ascription. Frontiers in Psychology, 6, 1184. https://doi.org/10.3389/fpsyg.2015.01184

Airenti, G. (2018). The development of anthropomorphism in interaction: Intersubjectivity, imagination, and theory of mind. Frontiers in Psychology, 9, 1-13. https://doi.org/10.3389/fpsyg.2018. 02136

Alagha, E. C., \& Helbing, R. R. (2019). Evaluating the quality of voice assistants' responses to consumer health questions about vaccines: An exploratory comparison of Alexa, Google assistant and Siri. BMJ Heal. Care Informatics, 26(e100075), 1-6. https://doi.org/10.1136/bmjhci-2019-100075

Alexander, T. M. (2006). Dewey, dualism, and naturalism. In J. R. Shook \& J. Margolis (Eds.), A Companion to Pragmatism (pp. 184-192). Blackwell Publishing.

Amazon Day One Staff. (2020). Amazon devices \& services news —September 2020. AboutAmazon.com https://www.aboutamazon.com/news/devices/amazon-devices-services-live-blog-september-2020 (

Ammari, T., Kaye, J., Tsai, J.Y., Bentley, F. (2019). Music, search, and IoT: How people (really) use voice assistants, ACM Trans. Comput. Interact., 26, 3. https://doi.org/10.1145/3311956.

Andics, A., Gábor, A., Gácsi, M., Faragó, T., Szabó, D., \& Miklósi, Á. (2016). Neural mechanisms for lexical processing in dogs. Science (80-. )., 353(6303), 1030-1032. https://doi.org/10.1126/scien ce.aaf3777

Atherton, G., \& Cross, L. (2018). Seeing more than human: Autism and anthropomorphic theory of mind. Frontiers in Psychology, 9, 1-18. https://doi.org/10.3389/fpsyg.2018.00528

Atran, S., \& Norenzayan, A. (2004). Religions evolutionary landscape: Counterintuition, commitment, compassion, communion. The Behavioral and Brain Sciences, 27(6), 713-730. https://doi.org/10. 1017/S0140525X04000172

Ayala, R.A. (2018). Thinking of conceptual reviews and systematic reviews. Nursing Inquiry, 25(4): e12264. https://doi.org/10.1111/nin.12264.

Bartneck, C., \& Hu, J. (2008). Exploring the abuse of robots. Interact. Stud. Soc. Behav. Commun. Biol. Artif. Syst., 9(3), 415-433. https://doi.org/10.1075/is.9.3.04bar

Bartneck, C., Bleeker, T., Bun, J., Fens, P., \& Riet, L. (2010). The influence of robot anthropomorphism on the feelings of embarrassment when interacting with robots. PALADYN J. Behav. Robot., 1(2), 109-115. https://doi.org/10.2478/s13230-010-0011-3

Beirl, D., Yuill, N., aRogers, Y. (2019). Using voice assistant skills in family life. In Proceedings of the 13th International Conference on Computer Supported Collaborative Learning - CSCL 2019, pp. 96-103.

Belpaeme, T., Kennedy, J., Ramachandran, A., Scassellati, B., \& Tanaka, F. (2018). Social robots for education: A review. Science robotics, 3(21), eaat5954. https://doi.org/10.1126/scirobotics.aat5954

Beneteau, E., Richards, O.K., Zhang, M., Kientz, J.A., Yip, J., \& Hiniker, A. (2019). Communication breakdowns between families and Alexa. In Proceedings of the 2019 CHI Conference on Human Factors in Computing Systems - CHI '19, pp. 1-13.

Bernstein, D., \& Crowley, K. (2008). Searching for signs of intelligent life: An investigation of young Children's beliefs about robot intelligence. The Journal of the Learning Sciences, 17(2), 225-247. https://doi.org/10.1080/10508400801986116

Bertenthal, B. I., Proffitt, D. R., Kramer, S. J., \& Spetner, N. B. (1987). Infants' encoding of kinetic displays varying in relative coherence. Developmental Psychology, 23(2), 171-178. https://doi.org/10. 1037/0012-1649.23.2.171

Bickmore, T., Gruber, A., \& Picard, R. (2005). Establishing the computer-patient working alliance in automated health behavior change interventions. Patient Education and Counseling, 59(1), 21-30.

Biele, C., Jaskulska, A., Kopec, W., Kowalski, J., Skorupska, K., \& Zdrodowska, A. (2019). How might voice assistants raise our children?. In International Conference on Intelligent Human Systems Integration. IHSI 2019. Advances in Intelligent Systems and Computing, pp. 162-167.

Branham, S., \& Mukkath Roy, A.R. (2019). Reading between the guidelines: How commercial voice assistant guidelines hinder accessibility for blind users. In The 21st International ACM SIGACCESS Conference on Computers and Accessibility, pp. 446-458, https://doi.org/10.1145/3308561. 3353797.

Breazeal, C. L. (2002). Designing sociable robots. MIT Press. 
Brink, K. A., Gray, K., \& Wellman, H. M. (2019). Creepiness creeps in: Uncanny Valley feelings are acquired in childhood. Child Development, 90(4), 1202-1214. https://doi.org/10.1111/cdev.12999

Bruni, D., Perconti, P., \& Plebe, A. (2018). Anti-anthropomorphism and its limits. Frontiers in Psychology, 9, 1-9. https://doi.org/10.3389/fpsyg.2018.02205

Caporael, L. R., \& Heyes, C. M. (1997). Why anthropomorphize? Folk psychology and other stories. In R. W. Mitchell, N. S. Thompson, \& H. L. Miles (Eds.), Anthropomorphism, anecdotes, and animals (pp. 59-74). State University of New York Press.

Castelli, F., Happé, F., Frith, U., \& Frith, C. (2000). Movement and mind: A functional imaging study of perception and interpretation of complex intentional movement patterns. Neuroimage, 12(3), 314-325. https://doi.org/10.1006/nimg.2000.0612

Castro-González, Á., Admoni, H., \& Scassellati, B. (2016). Effects of form and motion on judgments of social robots' animacy, likability, trustworthiness and unpleasantness. International Journal of Human Computer Studies, 90, 27-38. https://doi.org/10.1016/j.ijhcs.2016.02.004

Cave, R., \& Bloch, S. (2021). The use of speech recognition technology by people living with amyotrophic lateral sclerosis: A scoping review. Disability and Rehabilitation. Assistive Technology, 1-13. https://doi.org/10.1080/17483107.2021.1974961

Chaminade, T., Hodgins, J., \& Kawato, M. (2007). Anthropomorphism influences perception of computer-animated characters' actions. Social Cognitive and Affective Neuroscience, 2(3): 206216. https://doi.org/10.1093/scan/nsm017.

Chapman, M. (1988). Constructive evolution: Origins and development of Piaget's thought. Cambridge University Press.

Chin, H., Molefi, L.W., Yi, M.Y. (2020). Empathy is all you need: How a conversational agent should respond to verbal abuse. In Proceedings of the 2020 CHI Conference on Human Factors in Computing Systems - CHI '20, p. Paper 334, 13 pages. https://doi.org/10.1145/3313831.3376461.

Choi, J., \& Kim, M. (2009). The Usage and Evaluation of Anthropomorphic Form in Robot Desig. In Proceedings of the Undisciplined! Design Research Society Conference 2008.

Collins, E. C. (2017). Vulnerable users: Deceptive robotics. Conn. Sci., 29(3), 223-229. https://doi.org/ 10.1080/09540091.2016.1274959

Cosmides, L., Tooby, J., \& Barkow, J. H. (1992). Introduction: Evolutionary psychology and conceptual integration. In J. H. Barkow, L. Cosmides, \& J. Tooby (Eds.), The adapted mind: Evolutionary psychology and the generation of culture (pp. 3-15). Oxford University Press.

Cullen, H., Kanai, R., Bahrami, B., \& Rees, G. (2014). Individual differences in anthropomorphic attributions and human brain structure. Social Cognitive and Affective Neuroscience, 9(9): 1276-1280. https://doi.org/10.1093/scan/nst109

Damiano, L., \& Dumouchel, P. (2018). Anthropomorphism in human-robot co-evolution. Frontiers in Psychology, 9(March), 468. https://doi.org/10.3389/fpsyg.2018.00468

Davila-Ross, M., et al. (2014). Triggering social interactions: Chimpanzees respond to imitation by a humanoid robot and request responses from it. Animal Cognition, 17(3), 589-595. https://doi.org/ 10.1007/s10071-013-0689-9

de Graaf, M. M. A. (2016). An ethical evaluation of human-robot relationships. International Journal of Social Robotics, 8(4), 589-598. https://doi.org/10.1007/s12369-016-0368-5

de Visser, E. J., et al. (2016). Almost human: Anthropomorphism increases trust resilience in cognitive agents. Journal of Experimental Psychology, 22(3), 331-349. https://doi.org/10.1037/xap0000092

Descartes, R. (1988). The passions of the soul: A Reading of les passions de L'âme. Indianapolis: Hackett pub. Co (Original work published in 1649).

Descartes, R. (1998). Meditations and other metaphysical writings. Penguin Books (Original work published 1641).

DeVault, D. et al. (2014). SimSensei kiosk: A virtual human interviewer for healthcare decision support. In Proceedings of the 13th International Conference on Autonomous Agents and Multiagent Systems - AAMAS '14, pp. 1061-1068.

DiSalvo, C.F., Gemperle, F., Forlizzi, J., Kiesler, S. (2002). All robots are not created equal: the design and perception of humanoid robot heads. In Proceedings of the 4th Conference on Designing Interactive Systems: Processes, Practices, Methods, and Techniques, pp. 321-326. https://doi.org/10. $1145 / 778712.778756$.

Dousay, T.A., \& Hall, C. (2018). Alexa, tell me about using a virtual assistant in the classroom. In Proceedings of EdMedia + Innovate Learning. 
Dubal, S., Foucher, A., Jouvent, R., \& Nadel, J. (2011). Human brain spots emotion in non humanoid robots. Social Cognitive and Affective Neuroscience, 6(1), 90-97. https://doi.org/10.1093/scan/ nsq019

Duffy, B. R. (2003). Anthropomorphism and the social robot. Rob. Auton. Syst., 42(3-4), 177-190.

Duffy, O., Synnott, J., Mcnaney, R., Brito Zambrano, P., \& Kernohan, W.G. (2021). Attitudes Toward the Use of Voice-Assisted Technologies Among People With Parkinson Disease: Findings From a Web-Based Survey. JMIR Rehabil. Assistive Technology, 8(1): e23006. https://doi.org/10.2196/ 23006

Epley, N. (2018). A mind like mine: The exceptionally ordinary underpinnings of anthropomorphism. Journal of the Association for Consumer Research, 3(4), 591-598. https://doi.org/10.1086/699516

Epley, N., Waytz, A., \& Cacioppo, J. (2007). On seeing human: A three-factor theory of anthropomorphism. Psychological Review, 114(4), 864-886. https://doi.org/10.1037/0033-295X.114.4.864

Epley, N., Waytz, A., Akalis, S., \& Cacioppo, J. (2008). When we need a human: Motivational determinants of anthropomorphism. Social Cognition, 26(2), 143-155. https://doi.org/10.1521/soco.2008. 26.2.143

Evers, V., Maldonado, H., Brodecki, T., Hinds, P. (2008). Relational vs. group self-construal: Untangling the role of National Culture in HRI. In Proceedings of the 3rd ACM/IEEE International Conference on Human-Robot Interaction - HRI '08, pp. 255-262.

Eyssel, F.,d Reich, N. (2013). Loneliness makes the heart grow fonder (of robots) - On the effects of loneliness on psychological anthropomorphism. In Proceedings of the 8th ACM/IEEE International Conference on Human-Robot Interaction - HRI '08, pp. 121-122. https://doi.org/10.1109/ HRI.2013.6483531.

Eyssel, F., Hegel, F., Horstmann, G., Wagner, C. (2010). Anthropomorphic inferences from emotional nonverbal cues: A case study. In Proceedings of the 19th International Symposium in Robot and Human Interactive Communication, pp. 646-651.

Eyssel, F., De Ruiter, L., Kuchenbrandt, D., Bobinger, S., Hegel, F. (2012). If you sound like me, you must be more human': On the interplay of robot and user features on human-robot acceptance and anthropomorphism. In Proceedings of the 7th ACM/IEEE International Conference on HumanRobot Interaction - HRI '12, pp. 125-126. https://doi.org/10.1109/ICORR.2013.6650427.

Ferrari, F., Paladino, M. P., \& Jetten, J. (2016). Blurring human-machine distinctions: Anthropomorphic appearance in social robots as a threat to human distinctiveness. International Journal of Social Robotics, 8(2), 287-302.

Festerling, J., \& Siraj, I. (2020). Alexa, what are you? Exploring primary school Children's ontological perceptions of digital voice assistants in open interactions. Human Development, 64, 26-43. https://doi.org/10.1159/000508499

Fisher, J. A. (1996). The myth of anthropomorphism. In M. Bekoff \& D. Jamienson (Eds.), Readings in animal cognition (pp. 3-16). MIT Press.

Fong, T., Nourbakhsh, I., \& Dautenhahn, K. (2003). A survey of socially interactive robots. Rob. Auton. Syst., 42(3-4), 143-166. https://doi.org/10.1016/S0921-8890(02)00372-X

Gallagher, S. (2008). Direct perception in the intersubjective context. Consciousness and Cognition, 17(2), 535-543. https://doi.org/10.1016/j.concog.2008.03.003

Gao, Y., Pan, Z., Wang, H., \& Chen, G. (2018). Alexa, My Love: Analyzing Reviews of Amazon Echo. In Proceedings of the IEEE SmartWorld, Ubiquitous Intelligence \& Computing, Advanced \& Trusted Computing, Scalable Computing \& Communications, Cloud \& Big Data Computing, Internet of People and Smart City Innovation, pp. 372-380. https://doi.org/10.1109/SmartWorld.2018.00094.

Garg, R., \& Sengupta, S. (2020). He Is Just Like Me': A Study of the Long-Term Use of Smart Speakers by Parents and Children. In Proceedings of the ACM on Interactive, Mobile, Wearable and Ubiquitous Technologies, Vol. 4, No. 1, p. Article 11.

Gaudiello, I., Lefort, S., \& Zibetti, E. (2015). The ontological and functional status of robots: How firm our representations are? Comput. Human Behav., 50, 259-273. https://doi.org/10.1016/j.chb.2015. 03.060

Gazzola, V., Rizzolatti, G., Wicker, B., \& Keysers, C. (2007). The anthropomorphic brain: The mirror neuron system responds to human and robotic actions. Neuroimage, 35(4), 1674-1684. https://doi. org/10.1016/j.neuroimage.2007.02.003

Gobbini, M. I., et al. (2010). Distinct neural systems involved in agency and Animacy detection. Journal of Cognitive Neuroscience, 23(8), 1911-1920. https://doi.org/10.1162/jocn.2010.21574

Goetz, J., Kiesler, S., Powers, A. (2003). Matching robot appearance and behavior to tasks to improve human-robot cooperation. In Proceedings of The 12th IEEE International Workshop on Robot and 
Human Interactive Communication - 2003, pp. 55-60, doi: https://doi.org/10.1109/ROMAN.2003. 1251796.

Goudey, A., \& Bonnin, G. (2016). Must smart objects look human? Study of the impact of anthropomorphism on the acceptance of companion robots. Rech. Appl. en Mark. (English Ed.), 31(2), 2-20. https://doi.org/10.1177/2051570716643961

Guthrie, S. (1993). Faces in the clouds: A new theory of religion. Oxford University Press.

Ha, Q.-A., Chen, J.V., Uy, H.U., \& Capistrano, E.P. (2020). Exploring the privacy concerns in using intelligent virtual assistants under perspectives of information sensitivity and anthropomorphism," Int. J. Human-Computer Interact., pp. 1-16. https://doi.org/10.1080/10447318.2020.1834728.

Haack, S. (2006). Not cynicism, but Synechism: Lessons from classical pragmatism. In J. R. Shook \& J. Margolis (Eds.), A companion to pragmatism (pp. 141-153). Blackwell Publishing.

Hamlin, J. K., Wynn, K., \& Bloom, P. (2007). Social evaluation by preverbal infants. Nature, 450(7169), 557-559. https://doi.org/10.1038/nature06288

Harris, P. L. (2000). The work of the imagination. Blackwell Publishing.

Harwood, S., \& Eaves, S. (2020). Conceptualising technology, its development and future: The six genres of technology. Technological Forecasting and Social Change, 160, 120174. https://doi.org/10. 1016/j.techfore.2020.120174

Haun, D. B. M., Rapold, C. J., Call, J., Janzen, G., \& Levinson, S. C. (2006). Cognitive cladistics and cultural override in hominid spatial cognition. Proceedings of the National Academy of Sciences, 103(46), 17568-17573. https://doi.org/10.1073/pnas.0607999103

Herrmann, P., Atricia, S. R. W., \& Medin, D. L. (2010). Anthropocentrism is not the first step in children's reasoning about the natural world. Proceedings of the National Academy of Sciences, 107(22), 9979. https://doi.org/10.1073/pnas.1004440107

Herrmann, E., Call, J., Hernández-Lloreda, M. V., Hare, B., \& Tomasello, M. (2007). Humans have evolved specialized skills of social cognition: The cultural intelligence hypothesis. Science (80-. )., 317(5843), 1360-1366. https://doi.org/10.1126/science.1146282

Hirschberg, J., \& Manning, C. D. (2015). Advances in natural language processing. Science (80-), 349(6245), 261-266. https://doi.org/10.1002/9781405164535.ch14

Hoy, M. B. (2018). Alexa, Siri, Cortana, and more: An introduction to voice assistants. Medical Reference Services Quarterly, 37(1), 81-88. https://doi.org/10.1080/02763869.2018.1404391

Huston, A. C., \& Ripke, M. N. (2006). Developmental contexts in middle childhood: Bridges to adolescence and adulthood. Cambridge University Press.

James, W. (1967). The writings of William James: A (Comprehensive ed.). Random House.

James, W. (2010). Pragmatism: A new name for some old ways of thinking. The Floating Press (Original work published 1907).

James, W. (2012). Essays in Radical Empiricism. Auckland, New Zealand: The Floating Press (Original work published 1912).

James, W. (2013). The varieties of religious experience: A study in human nature, 2nd ed. Dover Publications (Original work published 1902).

Jargon, J. (2020). Kids' Chores Starting to Bore? New Apps, Assistants and Smart Appliances Can Motivate Them. The Wall Street Journal, New York, NY, US.

Jipson, J. L., Gülgöz, S., \& Gelman, S. A. (2016). Parent-child conversations regarding the ontological status of a robotic dog. Cognitive Development, 39, 21-35. https://doi.org/10.1016/j.cogdev.2016. 03.001

Kahn, P. H. J., Friedman, B., Pérez-Granados, D. R., \& Freier, N. G. (2006). Robotic pets in the lives of preschool children. Interact. Stud. Soc. Behav. Commun. Biol. Artif. Syst., 7(3), 405-436. https:// doi.org/10.1075/is.7.3.13kah

Kahn, P. H. J., et al. (2007). What is a human? - toward psychological benchmarks in the field of humanrobot interaction. Interaction Studies, 3(8), 363-390. https://doi.org/10.1109/ROMAN.2006. 314461

Kahn, P. H. J., Severson, R. L., \& Ruckert, J. H. (2009). The human relation with nature and technological nature. Current Directions in Psychological Science, 18(1), 37-42. https://doi.org/10.1111/j. 1467-8721.2009.01602.x

Kahn, P.H.J. et al. (2011). The new ontological category hypothesis in human-robot interaction. In Proceedings of the 6th Annual Conference for Basic and Applied Human-Robot Interaction Research - HRI'11, pp. 159-160. 
Kahn, P.H.J. et al. (2012a). Do people hold a humanoid robot morally accountable for the harm it causes?. In Proceedings of the 7th annual ACM/IEEE International Conference on Human-Robot Interaction - HRI '12, pp. 33-40. https://doi.org/10.1145/2157689.2157696.

Kahn, P. H. J., et al. (2012b). 'Robovie, you'll have to go into the closet now': Children's social and moral relationships with a humanoid robot. Developmental Psychology, 48(2), 303-314. https://doi.org/ $10.1037 / \mathrm{a} 0027033$

Kamide, H., Kawabe, K., Shigemi, S., \& Arai, T. (2013). Development of a psychological scale for general impressions of humanoid. Advanced Robotics, 27(1), 3-17. https://doi.org/10.1080/01691864. 2013.751159

Kanero, J., Geçkin, V., Oranç, C., Mamus, E., Küntay, A. C., \& Göksun, T. (2018). Social robots for early language learning: Current evidence and future directions. Child Development Perspectives, 12(3), 146-151. https://doi.org/10.1111/cdep.12277

Kiesler, S., \& Hinds, P. (2004). Introduction to this special issue on human-robot interaction. HumanComputer Interact., 19(1-2), 1-8. https://doi.org/10.1080/07370024.2011.556557

Kim, S., \& McGill, A.L. (2011). Gaming with Mr. slot or gaming the slot machine? Power, anthropomorphism, and risk perception. Journal of Consumer Research, 38(1), 94-107. https://doi.org/10.1086/ 658148.

Kim, M., Yi, S., \& Lee, D. (2019). Between living and nonliving: Young children's animacy judgments and reasoning about humanoid robots. PLoS One, 14(6), e0216869. https://doi.org/10.1371/journ al.pone.0216869

Kinsella, B., \& Mutchler, A. (2020). Smart speaker consumer adoption report. Voicebot.Ai.

Kissinger, P., et al. (1999). Application of computer-assisted interviews to sexual behavior research. American Journal of Epidemiology, 149(10), 950-954.

Kovacs, A. M., Teglas, E., \& Endress, A. D. (2010). The social sense: Susceptibility to others' beliefs in human infants and adults. Science (80-. )., 330(6012), 1830-1834. https://doi.org/10.1126/science. 1190792

Kwan, V. S. Y., Gosling, S. D., \& John, O. P. (2008). Anthropomorphism as a special case of social perception: A Cross-species social relations model analysis of humans and dogs. Social Cognition, 26(2), 129-142. https://doi.org/10.1521/soco.2008.26.2.129

Lee, K., Lee, K. Y., \& Sheehan, L. (2020). Hey Alexa! A magic spell of social glue?: Sharing a smart voice assistant speaker and its impact on users' perception of group harmony. Information Systems Frontiers, 22, 563-583. https://doi.org/10.1007/s10796-019-09975-1

Levillain, F., \& Zibetti, E. (2017). Behavioral objects: The rise of the evocative machines. J. HumanRobot Interact., 6(1), 4. https://doi.org/10.5898/jhri.6.1.levillain

Logg, J. M., Minson, J. A., \& Moore, D. A. (2019). Algorithm appreciation: People prefer algorithmic to human judgment. Organizational Behavior and Human Decision Processes, 151, 90-103. https:// doi.org/10.1016/j.obhdp.2018.12.005

Lopatovska, I., \& Williams, H., (2018). Personification of the Amazon Alexa: BFF or a mindless companion. In Proceedings of the 2018 Conference on Human Information Interaction \& Retrieval, pp. 265-268.

Lovato, S., \& Piper, A.M. (2015) Siri, is this you?': Understanding Young Children's Interactions with Voice Input Systems. In Proceedings of the 14th International Conference on Interaction Design and Children - IDC '15, pp. 335-338. https://doi.org/10.1145/2771839.2771910

Lovato, S.B., Piper, A.M., \& Wartella, E.A. (2019). Hey Google, do unicorns exist?: Conversational agents as a path to answers to Children's questions. In Proceedings of the 18th ACM International Conference on Interaction Design and Children, pp. 301-313.

Lucas, G. M., Gratch, J., King, A., \& Morency, L.-P. (2014). It's only a computer: Virtual humans increase willingness to disclose. Comput. Human Behav., 37, no. C, 94-100. https://doi.org/10. 1016/j.chb.2014.04.043

McDermid, D. (2006). The varieties of pragmatism: Truth, realism, and knowledge from James to Rorty. Bloomsbury Publishing.

Medin, D., Waxman, S., Woodring, J., \& Washinawatok, K. (2010). Human-centeredness is not a universal feature of young children's reasoning: Culture and experience matter when reasoning about biological entities. Cognitive Development, 25(3), 197-207. https://doi.org/10.1016/j.cogdev.2010. 02.001

Melson, G. F., et al. (2009). Children's behavior toward and understanding of robotic and living dogs. Journal of Applied Developmental Psychology, 30, 92-102. https://doi.org/10.1016/j.appdev.2008. 10.011 
Meltzoff, A. N., Brooks, R., Shon, A. P., \& Rao, R. P. N. (2010). 'Social' robots are psychological agents for infants: A test of gaze following. Neural Networks, 23(8-9), 966-972. https://doi.org/10.1016/j. neunet.2010.09.005

Meurisch, C. et al. (2020). Exploring User Expectations of Proactive AI Systems. In Proceedings of the ACM on Interactive, Mobile, Wearable and Ubiquitous Technologies, p. Article 146. https://doi. org/10.1145/3432193

Misak, C. J. (2006). Scientific realism, anti-realism, and empiricism. In J. R. Shook \& J. Margolis (Eds.), A companion to pragmatism (pp. 398-409). Blackwell Publishing.

Moar, J., \& Escherich, M. (2020). Voice assistant market: Player strategies, Monetisation \& Market Size 2020-2024. Juniper Research. https://www.juniperresearch.com/press/press-releases/number-ofvoice-assistant-devices-in-use (accessed Dec. 31, 2020).

Mori, M. (2012). The Uncanny Valley. IEEE Robotics and Automation Magazine, 19(2), 33-35. https:// doi.org/10.1109/MRA.2012.2192811

Motalebi, N., Cho, E., Sundar, S.S., \& Abdullah, S. (2019). Can Alexa be your therapist?: How Backchanneling transforms smart-speakers to be active listeners. In Conference Companion Publication of the 2019 on Computer Supported Cooperative Work and Social Computing, pp. 309-313.

Mutlu, B., Yamaoka, F., Kanda, T., Ishiguro, H., Hagita, N. (2009). Nonverbal leakage in robots: Communication of intentions through seemingly unintentional behavior. In Proceedings of the 4th ACM/IEEE International Conference on Human Robot Interaction - HRI '09, pp. 69-76.

Nass, C. I., \& Brave, S. (2005). Wired for speech: How voice activates and advances the human-computer relationship. MIT Press.

Nass, C.I., Steuer, J., Tauber, E., Reeder, H., Jonathan Tauber, E.R.N.C.S. (1993). "Computers Agency , \& Ethopoeia: Computers as Social Actors. Proc. Conf. Companion Hum. Factors Comput. Syst. INTERACT '93 CHI '93, pp. 111-112. https://doi.org/10.1145/259964.260137.

Nass, C.I., Steuer, J., Tauber, E.R. (1994). Computers are social actors. In Proceedings of the SIGCHI Conference on Human Factors in Computing Systems, pp. 72-78.

Nass, C. I., Fogg, B. J., \& Moon, Y. (1996). Can computers be teammates? International Journal of Human Computer Studies, 45(6), 669-678.

Nass, C. I., Moon, Y., \& Carney, P. (1999). Are respondents polite to computers? Responses to computerbased interviewing systems. Journal of Applied Social Psychology, 29(5), 1093-1110.

Norman, D. A. (2005). Emotional design: Why we love (or hate) everyday things. BasicBooks.

Onishi, K. H., \& Baillargeon, R. (2005). Do 15-month-old infants understand false beliefs? Science (80-. )., 308(5719), 255-258. https://doi.org/10.1126/science.1107621

Oranç, C., \& Küntay, A. C. (2020). Children's perception of social robots as a source of information across different domains of knowledge. Cognitive Development, 54, 100875. https://doi.org/10. 1016/j.cogdev.2020.100875

Papadopoulos, I., Lazzarino, R., Miah, S., Weaver, T., Thomas, B., \& Koulouglioti, C. (2020). A systematic review of the literature regarding socially assistive robots in pre-tertiary education. Computers in Education, 155, 103924. https://doi.org/10.1016/j.compedu.2020.103924

Papert, S. (1980). Mindstorms: Children, computers, and powerful ideas. Basic Books.

Parsons, S. (2016). Authenticity in virtual reality for assessment and intervention in autism: A conceptual review. Educational Research Review, 19, 138-157. https://doi.org/10.1016/j.edurev.2016.08.001

Paul, C. D., Thomas, E. V., Doulin, A. M., Hussain, S. Z., \& Jimenez, E. (2021). Using wireless technology to support social connectedness in individuals with intellectual and developmental disabilities: A focus group study. Journal of Special Education Technology, 1-10. https://doi.org/10.1177/ 01626434211004133

Pearson, Y., \& Borenstein, J. (2014). Creating 'companions' for children: The ethics of designing esthetic features for robots. AI \& Society, 29(1), 23-31. https://doi.org/10.1007/s00146-012-0431-1

Perez, S. (2019). Amazon Launches Medication Management Features for Alexa. TechCrunch. https:// techcrunch.com/2019/11/26/amazon-launches-medication-management-features-for-alexa/

Perner, J., \& Roessler, J. (2012). From infants' to children's appreciation of belief. Trends in Cognitive Sciences, 16(10), 519-525. https://doi.org/10.1016/j.tics.2012.08.004

Porcheron,M., Fischer, J.E., Reeves, S., \& Sharples, S. (2018). Voice interfaces in everyday life. In Proceedings of the 2018 CHI Conference on Human Factors in Computing Systems - CHI '18, pp. 1-12. https://doi.org/10.1145/3173574.3174214

Porra, J., Lacity, M., \& Parks, M. S. (2020). 'Can computer based human-likeness endanger humanness?' - A philosophical and ethical perspective on digital assistants expressing feelings they Can't have. Information Systems Frontiers, 22, 533-547. https://doi.org/10.1007/s10796-019-09969-z 
Pradhan, A., Mehta, K., \& Findlater, L. (2018). Accessibility Came by Accident': Use of Voice-Controlled Intelligent Personal Assistants by People with Disabilities. Proceedings of the $2018 \mathrm{CHI}$ Conference on Human Factors in Computing Systems. ACM, pp. 1-13, Paper No.: 459. https://doi. org/10.1145/3173574.3174033

Pradhan, A., Findlater, L., \& Lazar, A. (2019). Phantom Friend or Just a Box with Information: Personification and Ontological Categorization of Smart Speaker-based Voice Assistants by Older Adults. In Proceedings of the ACM on Human-Computer Interaction, p. Vol. 3, No. CSCW, Article 214.

Purington, A., Taft, J.G., Sannon, S., Bazarova, N.N., Taylor, S.H. (2017). Alexa is my new BFF': Social roles, user satisfaction, and personification of the Amazon Echo. In Proceedings of the ACM CHI Conference on Human Factors in Computing Systems - CHI '17, vol. Part F1276, pp. 2853-2859. https://doi.org/10.1002/ece3.1301

Reeves, B., \& Nass, C. I. (1996). The media equation: How people treat computers, television, and new media like real people and places. Cambridge University Press.

Reiss, D. (2017). Anthropomorphism. In J. Brockman (Ed.), This idea is brilliant: Lost, overlooked, and underappreciated scientific concepts everyone should know (pp. 242-244).

Rescher, N. (2006). Pragmatic idealism and metaphysical realism. In J. R. Shook \& J. Margolis (Eds.), $A$ companion to pragmatism (pp. 386-397). Blackwell Publishing.

Riether, N., Hegel, F., Wrede, B., Horstmann, G. (2012). Social facilitation with social robots?. In Proceedings of the 7th ACM/IEEE International Conference on Human-Robot Interaction - HRI '12, pp. 41-47, doi: https://doi.org/10.1145/2157689.2157697.

Rorty, R. (1982). Consequences of pragmatism: Essays, 1972-1980. University of Minnesota Press.

Rorty, R. (1998). Pragmatism. In Routledge Encyclopedia of Philosophy, Taylor \& Francis.

Rorty, R. (2006). Pragmatism as anti-authoritarianism. In J. R. Shook \& J. Margolis (Eds.), A companion to pragmatism (pp. 257-266). Blackwell Publishing.

Ross, C. (2019). New voices at patients' bedsides: Amazon, Google, Microsoft, and apple," STAT. https://www.statnews.com/2019/02/06/voice-assistants-at-bedside-patient-care/?utm_campaign= the_download.unpaid.engagement\&utm_source=hs_email\&utm_medium=email\&utm_content= 69643770\&_hsenc=p2ANqtz\%2D\%2DnOHcxWiobOCFlnUebi0I5Zc_2HUuv1GHj1PLxaPehTUo jtzL-mYVdu0NjNz (accessed Jan. 20, 2021).

Rücker, M. T., \& Pinkwart, N. (2016). Review and discussion of Children's conceptions of computers. Journal of Science Education and Technology, 25, 274-283. https://doi.org/10.1007/ s10956-015-9592-2

Sætra, H. S. (2020). The parasitic nature of social AI: Sharing minds with the mindless. Integrative Psychological \& Behavioral Science, 54(2), 308-326. https://doi.org/10.1007/s12124-020-09523-6

Sætra, H. S. (2021a). Robotomorphy. AI Ethics. https://doi.org/10.1007/s43681-021-00092-X

Sætra, H. S. (2021b). Challenging the neo-anthropocentric relational approach to robot rights. Frontiers in Robotics and AI, 8, 301. https://doi.org/10.3389/frobt.2021.744426

Scheele, D., Schwering, C., Elison, J. T., Spunt, R., Maier, W., \& Hurlemann, R. (2015). A human tendency to anthropomorphize is enhanced by oxytocin. European Neuropsychopharmacology, 25(10), 1817-1823. https://doi.org/10.1016/j.euroneuro.2015.05.009

Schmitz, M. (2010). Concepts for life-like interactive objects. In Proceedings of the 5th International Conference on Tangible, Embedded, and Embodied Interaction, pp. 157-164. https://doi.org/10. 1145/1935701.1935732.

Sciuto, A., Saini, A., Forlizzi, J., Hong, J.I. (2018). Hey Alexa, What's up?: A mixed-methods studies of in-home conversational agent usage. In Proceedings of the 2018 Designing Interactive Systems Conference, pp. 857-868, https://doi.org/10.1145/3196709.3196772.

Seibt, J. (2017). Towards an ontology of simulated social interaction: Varieties of the 'as if' for robots and humans. In R. Hakli \& J. Seibt (Eds.), Sociality and normativity for robots: Philosophical inquiries into human-robot interactions (pp. 11-39). Springer International Publishing.

Servais, V. (2018). Anthropomorphism in Human-Animal Interactions: A Pragmatist View. Frontiers in Psychology, vol. 9, pp. 1-10. https://doi.org/10.3389/fpsyg.2018.02590

Severson, R. L., \& Carlson, S. M. (2010). Behaving as or behaving as if? Children's conceptions of personified robots and the emergence of a new ontological category. Neural Networks, 23(8-9), 10991103. https://doi.org/10.1016/j.neunet.2010.08.014

Severson, R. L., \& Lemm, K. M. (2016). Kids see human too: Adapting an individual differences measure of anthropomorphism for a child sample. Journal of Cognition and Development, 17(1), 122141. https://doi.org/10.1080/15248372.2014.989445 
Severson, R. L., \& Woodard, S. R. (2018). Imagining others' minds: The positive relation between Children's role play and anthropomorphism. Frontiers in Psychology, 9, 1-16. https://doi.org/10.3389/ fpsyg.2018.02140

Sezgin, E., et al. (2020). Capturing at-home health and care information for children with medical complexity using voice interactive technologies: Multi-stakeholder viewpoint. Journal of Medical Internet Research, 22(2), e14202. https://doi.org/10.2196/14202

Shah, J., Wiken, J., Williams, B., Breazeal, C. (2011). Improved human-robot team performance using Chaski, a human-inspired plan execution system. In Proceedings of the 6th International Conference on Human-Robot Interaction - HRI'11, pp. 29-36.

Shaman, N. J., Saide, A. R., \& Richert, R. A. (2018). Dimensional structure of and variation in anthropomorphic concepts of god. Frontiers in Psychology, 9, 1-16. https://doi.org/10.3389/fpsyg.2018. 01425

Sharkey, N., \& Sharkey, A. (2010). The crying shame of robot nannies: An ethical appraisal. Interaction Studies, 11(2), 161-190.

Simion, F., Regolin, L., \& Bulf, H. (2008). A predisposition for biological motion in the newborn baby. Proceedings of the National Academy of Sciences, 105(2), 809-813. https://doi.org/10.1073/pnas.07070 21105

Skidmore, L., Moore, R.K. (2019). Using Alexa for Flashcard-based Learning. Proc. 20th Annu. Conf. Int. Speech Commun. Assoc. - Interspeech 2019, pp. 1846-1850.

Small, C.E., Nigrin, D., Churchwell, K., Brownstein, J. (2018). What will health care look like once smart speakers are everywhere?. Harvard Business Review. https://hbr.org/2018/03/what-will-health-carelook-like-once-smart-speakers-are-everywhere (accessed Feb. 28, 2019).

Southgate, V., Senju, A., \& Csibra, G. (2007). Action anticipation through attribution of false belief by 2-year-olds. Psychological Science, 18(7), 587-592. https://doi.org/10.1111/j.1467-9280.2007. 01944.x

Sprigge, T. L. S. (2006). James, empiricism, and absolute idealism. In J. R. Shook \& J. Margolis (Eds.), $A$ companion to pragmatism (pp. 166-176). Blackwell Publishing.

Suckiel, E. K. (2006). William James. In J. R. Shook \& J. Margolis (Eds.), A companion to pragmatism (pp. 30-43). Blackwell Publishing.

Sweeney, M., \& Davis, E. (2020). Alexa, are you listening? An exploration of smart voice assistant use and privacy in libraries. Information Technology and Libraries, 39(4), 1-21. https://doi.org/10.6017/ital. v39i4. 12363

Timpano, K. R., \& Shaw, A. M. (2013). Conferring humanness: The role of anthropomorphism in hoarding. Pers. Individ. Dif., 54(3), 383-388. https://doi.org/10.1016/j.paid.2012.10.007

Triberti, S., Chirico, A., La Rocca, G., \& Riva, G. (2017). Developing emotional design: Emotions as cognitive processes and their role in the Design of Interactive Technologies. Frontiers in Psychology, 8, 1773. https://doi.org/10.3389/fpsyg.2017.01773

Trippas, J.R. et al. (2019). Learning about work tasks to inform intelligent assistant design. In Proceedings of the 2019 Conference on Human Information Interaction and Retrieval - CHIIR '19, pp. 5-14.

Trivedi, N. (2018). ProblemPal: Generating autonomous practice content in real-time with voice commands and Amazon Alexa. In Proceedings of the World Conference on E-Learning in Corporate, Government, Healthcare, and Higher Education, pp. 80-82.

Turk, V. (2016). Home invasion. New Scientist (1971), 232(3104-3106), 16-17. https://doi.org/10.1016/ S0262-4079(16)32318-1

Turkle, S. (2005). The second self: Computers and the human Spirit. The MIT Press (Original work published 1984).

Turkle, S. (2017). Alone together (2nd ed.). Basic Books.

Turkle, S. (2018). There will never be an age of artificial intimacy, The New York Times, . https://www. nytimes.com/2018/08/11/opinion/there-will-never-be-an-age-of-artificial-intimacy.html (Accessed 17 Feb 2019).

UNESCO and EQUALS Skills Coalition. (2019). I'd blush if I could. UNESCO https://unesdoc.unesco.org/ ark:/48223/pf0000367416.page=1 (accessed May 23, 2020)

Urquiza-Haas, E. G., \& Kotrschal, K. (2015). The mind behind anthropomorphic thinking: Attribution of mental states to other species. Animal Behaviour, 109, 167-176. https://doi.org/10.1016/j.anbehav. 2015.08.011

Van Overwalle, F., \& Baetens, K. (2009). Understanding others' actions and goals by mirror and mentalizing systems: A meta-analysis. Neuroimage, 48(3), 564-584. https://doi.org/10.1016/j.neuroimage.2009. 06.009 
van Straten C., Peter J., Kühne R., Barco A. (2020). Transparency about a Robot's Lack of Human Psychological Capacities: Effects on Child-Robot Perception and Relationship Formation. In Proceedings of the ACM Transactions on Human-Robot Interaction, Vol. 9, No. 2, p. Article 11.

Varella, M. A. C. (2018). The biology and evolution of the three psychological tendencies to anthropomorphize biology and evolution. Frontiers in Psychology, 9, 1-21. https://doi.org/10.3389/fpsyg.2018. 01839

Vlahos, J. (2019). Talk to me: How voice computing will transform the way we live, work, and think. Houghton Mifflin Harcourt.

Voit, A., Niess, J., Eckerth, C., Ernst, M., Weingärtner, H., Woundefinedniak, P. (2020). It's not a romantic relationship': Stories of adoption and abandonment of smart speakers at home. In Proceedings of the 19th International Conference on Mobile and Ubiquitous Multimedia - MUM '20, pp. 71-82.

Wagner, K., Schramm-Klein, H. (2019). Alexa, are you human? Investigating anthropomorphism of digital voice assistants - a qualitative approach. In Fortieth International Conference on Information Systems, pp. $1-17$.

Walters, M. L., Syrdal, D. S., Dautenhahn, K., Te Boekhorst, R., \& Koay, K. L. (2008). Avoiding the Uncanny Valley - Robot appearance, personality and consistency of behavior in an attention-seeking home scenario for a robot companion. Auton. Robots, 24(2), 159-178. https://doi.org/10.1007/ s10514-007-9058-3

Wang, W. (2017). Smartphones as social actors? Social dispositional factors in assessing anthropomorphism. Comput. Human Behav., 68, 334-344. https://doi.org/10.1016/j.chb.2016.11.022

Wang, L. (2020). The Three Harms of Gendered Technology. Australas. J. Inf. Syst., vol. 24, no. Selected papers from the 2019 AiCE Conference, pp. 1-9, https://doi.org/10.3127/ajis.v24i0.2799.

Wang, A., Sunshine, J.E., \& Gollakota, S. (2019a). Contactless infant monitoring using white noise. In Proceedings of the 25th Annual International Conference on Mobile Computing and Networking - MobiCom'19, 52, https://doi.org/10.1145/3300061.3345453.

Wang, F., Tong, Y., \& Danovitch, J. (2019b). Who do I believe? Children's epistemic trust in internet, teacher, and peer informants. Cognitive Development, 50, 248-260.

Waytz, A., \& Mitchell, J. P. (2011). Two mechanisms for simulating other minds: Dissociations between mirroring and self-projection. Current Directions in Psychological Science, 20(3), 197-200. https://doi. org/10.1177/0963721411409007

Waytz, A., Morewedge, C., Epley, N., Monteleone, G., Gao, J.-H., \& Cacioppo, J. (2010a). Making sense by making sentient: Effectance motivation increases anthropomorphism. Journal of Personality and Social Psychology, 99(3), 410-435. https://doi.org/10.1037/a0020240

Waytz, A., Gray, K., Epley, N., \& Wegner, D. M. (2010b). Causes and consequences of mind perception. Trends in Cognitive Sciences, 14(8), 383-388. https://doi.org/10.1016/j.tics.2010.05.006

Waytz, A., Heafner, J., \& Epley, N. (2014a). The mind in the machine: Anthropomorphism increases trust in an autonomous vehicle. Journal of Experimental Social Psychology, 52, 113-117. https://doi.org/10. 1016/j.jesp.2014.01.005

Waytz, A., Cacioppo, J., \& Epley, N. (2014b). Who sees human? The stability and importance of individual differences in anthropomorphism. Perspectives on Psychological Science, 5(3), 219-232. https://doi. org/10.1177/1745691610369336. Who

Waytz, A., Cacioppo, J.T., Hurlemann, R., Castelli, F., Adolphs, R., \& Paul, L.K. (2019). Anthropomorphizing without social cues requires the basolateral amygdala. Journal of Cognitive Neuroscience, 31(4): 482-496. https://doi.org/10.1162/jocn_a_01365

Wellman, H. M. (2014). Making minds: How theory of mind develops. Oxford University Press.

Woods, S. (2006). Exploring the design space of robots: Children's perspectives. Interacting with Computers, 18(6), 1390-1418. https://doi.org/10.1016/j.intcom.2006.05.001

Xu, Y., Wang, D., Collins, P., Lee, H., \& Warschauer, M. (2021). Same benefits, different communication patterns: Comparing Children's reading with a conversational agent vs. a human partner. Computers in Education, 161, 104059. https://doi.org/10.1016/j.compedu.2020.104059

Yip, J.C. et al. (2019). Laughing is Scary, but Farting is Cute: A Conceptual Model of Children's Perspectives of Creepy Technologies. In Proceedings of the 2019 CHI Conference on Human Factors in Computing Systems - CHI '19, pp. 1-15, https://doi.org/10.1145/3290605.3300303.

Yokotani, K., Takagi, G., \& Wakashima, K. (2018). Advantages of virtual agents over clinical psychologists during comprehensive mental health interviews using a mixed methods design. Comput. Human Behav., 85, 135-145. https://doi.org/10.1016/j.chb.2018.03.045 
Yuan, Y., et al. (2019). Speech interface reformulations and voice assistant personification preferences of children and parents. Int. J. Child-Computer Interact., 21, 77-88. https://doi.org/10.1016/j.ijcci.2019. 04.005

Złotowski, J., Strasser, E., Bartneck, C. (2014). Dimensions of Anthropomorphism: From Humanness to Humanlikeness. In Proceedings of the 14th International Conference on Human-Robot Interaction ICM / IEEE 2014, pp. 66-73. https://doi.org/10.1145/2559636.2559679.

Złotowski, J., Proudfoot, D., Yogeeswaran, K., \& Bartneck, C. (2015). Anthropomorphism: Opportunities and challenges in human - Robot interaction. International Journal of Social Robotics, 7, 347-360. https://doi.org/10.1007/s12369-014-0267-6

Publisher's Note Springer Nature remains neutral with regard to jurisdictional claims in published maps and institutional affiliations.

Janik Festerling is a doctoral student at the Department of Education at the University of Oxford. His research attempts to develop a theoretical as well as empirical understanding of what role voice assistants play in today's home and childhood environments, and how exposure to these machines is related to the way children construct basic understandings of the world around them.

Iram Siraj is Professor of Child Development and Education at the Department of Education at the University of Oxford. She is an expert on pre-school and primary school children's learning and she is currently leading interventions supporting children's language and math learning via teacher professional development. She is coordinator of the Child Development and Learning research group and the department's Language, Cognition and Development research theme. She has an interest in the mechanisms by which children acquire new learning.

\title{
Authors and Affiliations
}

\author{
Janik Festerling ${ }^{1}$ (D) Iram Siraj ${ }^{1}$ \\ Iram Siraj \\ Iram.siraj@education.ox.ac.uk \\ 1 Department of Education, University of Oxford, 15 Norham Gardens, Oxford OX2 6PY, UK
}

